Portland State University

PDXScholar

\title{
Ideas in Dialogue: Leveraging the Power of Child-Led Storytelling in the Multicultural Preschool Classroom
}

\author{
Erin E. Flynn \\ Portland State University, flynn2@pdx.edu
}

Follow this and additional works at: https://pdxscholar.library.pdx.edu/socwork_fac

Part of the Bilingual, Multilingual, and Multicultural Education Commons, and the Early Childhood Education Commons

Let us know how access to this document benefits you.

\section{Citation Details}

Flynn, Erin E., "Ideas in Dialogue: Leveraging the Power of Child-Led Storytelling in the Multicultural Preschool Classroom" (2018). Social Work Faculty Publications and Presentations. 244.

https://pdxscholar.library.pdx.edu/socwork_fac/244 


\title{
Ideas in Dialogue: Leveraging the Power of Child-Led Storytelling in the Multicultural Preschool Classroom
}

\author{
Erin Elizabeth Flynn \\ Assistant Professor of Child, Youth, \& Family Studies \\ Portland State University \\ PO Box 751 \\ Mailcode: SSW \\ SSW Portland, OR 97207 \\ flynn2@pdx.edu
}

The article has been accepted for publication and will appear in a revised form, subsequent to editorial input by Cambridge University Press, in Language in Society published by Cambridge University Press. COPYRIGHT: (C) Cambridge University Press 2018

Flynn, E. E. (2018). Ideas in dialogue: Leveraging the power of child-led storytelling in the multicultural preschool classroom. Language in Society, 47(4), 601-633. doi:10.1017/ S0047404518000593 


\section{ABSTRACT}

An investigation into the interactive features of small group, child-led storytelling in preschool classrooms serving lower socioeconomic status (SES), multilingual children shows both the affordances and constraints of positioning children to author their own experiences in the classroom. In story circles, children told stories which included canonical instantiations of story and culturally-shaped features. Through their stories, the children advanced ideas, built connections, and evaluated ways of telling stories as they continued ideas like threads from story to story. Child-led storytelling did not disrupt the dynamics of power through which some ways of using language are privileged while others are marginalized. Instead, story circles simply shifted children' relationship to the process of being and becoming literate such that children did the evaluating, valuing, and promoting of ways of using language, developing literate identities, but potentially forestalling some ways of participating even as shared interactional norms were developed.

Key words: storytelling, multicultural, early childhood education 


\section{Ideas in Dialogue: Leveraging the Power of Child-Led Storytelling in the Multicultural Preschool Classroom}

\section{INTRODUCTION}

Early childhood classrooms have long been envisioned as critical sites for building the facility with language necessary for later high level literacy practices like the capacity to compose and comprehend texts (Dickinson 2011; Dickinson \& Porche 2011). To build this facility, children need opportunities to use language that extends a topic, allowing children to build on an idea (Hoff-Ginsberg 1991; Weizman \& Snow 2001; Snow \& Beals 2006; Dickinson 2011; Dickinson \& Porche 2011). Extending a topic encourages the use of more complex grammatical structures, creating the kind of syntactic complexity associated with language learning (Huttenlocher, Vasilyeva, Cymerman, \& Levine 2002; Justice, McGinty, Zucker, Cabell, \& Piasta 2013). Extending a topic to build on an idea invites children to practice the patterned ways that language unfolds in academic genres like reports and different forms of story (Martin \& Rose 2008; Christie 2012). Sustaining ideas also allows young children to practice achieving thematic continuity and relevance, both of which are needed to maintain and extend discussions (Küntay \& Şenay 2003).

Creating the space for children to extend ideas, constructing meaning through language, is not a neutral activity because language is not 'some neutral commodity which carries "content" (Christie 2013:18). Instead, language is always used to fulfill some social purpose with power being exercised in largely invisible and taken for granted ways. This can be especially true in classrooms, where ways of using language by the dominant cultural group are treated as universal or ideal ways of using language. 
Centering primarily White, middle class discourse patterns as normal and ideal ways of construing experience marginalizes the ways of saying, doing, and being that many lower socioeconomic status (SES), multilingual children bring to early schooling (Souto-Manning, Dernikos, \& Yu 2016). The aim of this study is to make visible the sophistication of young children's engagement in an ongoing storytelling activity, overturning deficit conceptions of lower SES, multilingual children by showing how children's complex contributions navigate the tension between expectation and invention when children are given the space to story their experiences.

Storytelling offers unique potential as a vehicle for agentic language learning that encourages a repertoire of ways of making meaning (see Schick \& Melzi 2010 for review of the development of oral narratives). Children as young as two years old have demonstrated the capacity to marshal the foundations of storytelling in their everyday interactions (Engel 1997) and even in their private talk (Nelson 2006). Further, much of the familial talk that children engage in, like talk that occurs during daily meals, occurs in the form of story (Snow \& Beals 2006), exposing children to a large number of stories in the home, community, and school (Rogoff 2003). In this respect, storytelling offers a known form that lower SES, multilingual children can rely on as an entry point to participating in extended classroom discussions that continue ideas.

Young children's storytelling has been analyzed as a primarily monologic event with children's stories considered in relation to idealized story structures (Stein \& Glenn 1979; Peterson \& McCabe 1983, 1991; McCabe \& Peterson 1991; Stein \& Albro 1994, 1997) and culturally shaped meaning-making patterns (Michaels 1981, 2006; Minami \& McCabe 1991; Au 
1993; Hyon \& Sulzby 1994; Jimenez-Silva \& McCabe 1996; McCabe 1997; Champion, Katz, Muldrow, \& Dail, 1999; Cazden 2001; Minami 2002; Champion 2003; Bliss \& McCabe 2008;

Cheatham \& Jimenez-Silva 2011). Linguists working in the tradition of systemic functional linguistics (SFL) investigate story from a genre-focused perspective, envisioning expert storytelling as varied in form, dependent on purpose, and responsive to context (Martin 1984; Rothery \& Stenglin 1997; Plum 2004; Martin \& Rose 2008). Other research has shown the community building potential of storytelling in the classroom, showing the valuable connection between story and play (Paley 1984, 1986, 1990; McNamee 1990, 1992; Nicolopoulou, McDowell, \& Brockmeyer 2006). Such studies show the way that children express identity, build and maintain social relationships, and entertain one another through classroom storytelling opportunities (Champion et al. 1999).

This study investigates the interactive affordances of small group storytelling, envisioning storytelling as purposeful social activity which unfolds in waves of information. Children construe experience in distinct patterns or genres of story (see Martin \& Rose 2008 for discussion), using language in ways informed by the priorities and expectations of cultural communities (See McCabe 1997 for overview), while dialogically responding to stories told in the course of ongoing interaction (Küntay \& Şenay 2003). To show the way that even young children's stories are carefully constructed, patterned ways of using language, culturally informed, and dialogically related, this study examines stories in terms of genre, culturallyshaped features, ideational threads, and comments.

Story genres 
Stories recapitulate a past event, conveying both what happened and the significance of its occurrence (Labov \& Waletzky 1967). Evidence from the stories of children (Martin 1984; Martin \& Rose 2008) and adults (Rothery \& Stenglin 1997; Plum 2004; Eggins \& Slade 2005) shows that there are multiple genres of story, that story is an umbrella term for a number of distinct types of ways to recapitulate past experience (Martin \& Rose 2008). Three common genres of story are the narrative, recount, and observation (Rothery \& Stenglin 1997; Martin 1984; Plum 2004; Martin \& Rose 2008). Young children have been documented telling these types of stories in ways that reflect a budding sophistication with valued patterns of meaningmaking (Flynn In press).

In SFL, genres are understood as staged, goal oriented activity through which social processes occur (Martin 2009). Genres consist of types of texts which reflect the shared ways of getting things done that emerge in a culture. From this view, learning to construct, reproduce, and vary genres is a central task of schooling since it reflects a child's ability to share meanings in ways that can be readily understood by others. Though any one genre has many possible realizations, each genre of story has what is recognized as a prototypical instantiation evident in its underlying structure. The middle stages of each genre of story are thought to be elemental or defining.

One of the most enduring conceptions of story - the narrative as articulated by Labov and Waletzky (1967) - describes stories that unfold as a temporal sequence of events. Labov and Waletzky define narrative stories as unfolding through the basic underlying structure of orientation, complicating action, evaluation, resolution, and an optional coda. Orientations establish experiential context for events by indicating the people, places, times, and behavioral 
situation for what is about to unfold. Complicating actions consist of a series of events which unfold in the order in which they occurred. Evaluation reveals the attitude of the storyteller toward the events. Evaluation can occur throughout the narrative, but structurally follows the complicating action in a complete narrative to temporarily suspend the action and emphasize the extent of the complicating action. Resolutions indicate the result of the complicating action. Codas return events to the present moment.

SFL both draws on and departs from Labov and Waletzky's classic articulation of narrative structure, drawing a distinction between stories that unfold as a series of events (recount stories) and stories that consist of a problem or challenge and its resolution (narrative stories). For instance, in SFL, complications in narrative stories consist of events which introduce challenges, problems, or moments that counter our expectations (Rothery \& Stenglin 1997). Just as in Labov and Waletzky's formulation, in narratives suspense is sustained by an evaluation stage which forestalls addressing the complication by providing an interpersonal perspective or appraisal of the event. In SFL, the resolution brings the complication to a satisfactory settlement. If complications counter our expectations, then resolutions bring events back in line with our expectations. Thus, in SFL, narrative stories deal with and evaluate problematic events and their outcome (Rothery \& Stenglin 1997).

In contrast, recount stories unfold through a temporal succession of events, giving the events significance (Rothery \& Stenglin 1997). The recount genre of story structurally unfolds as an orientation, series of events, and reorientation which brings the audience back to the experiential starting point. Recounts stories have also been shown to end with a naturally 
concluding event like returning home or evening falling. Such events are understood by members of shared culture to bring closure to what has been relayed.

As a genre, observation stories describe a scene or situation, offering a highly personal response. Observations are stories that structurally unfold through an orientation stage, a descriptive stage, and a concluding comment or evaluation which makes the interpersonal significance of events explicit. Observation stories use descriptive power to share a slice of life, deeply describing an instance and its significance rather than construing experience as unfolding through events.

A significant insight offered by genre-focused approaches to story is that these distinct patterns of deploying language demonstrate equally valid variations in construing experience (Flynn In press). Rather than elevating a single meaning-making pattern as an idealized, or preeminent form of story, a genre-focused approach uncovers the choices at storytellers' disposal, and the way, that these choices are informed by context and purpose.

\section{Culturally-shaped features of language}

Children are enculturated into diverse ways of storying experience, internalizing expectations and values about how and what to talk about in story situations (Heath 1983; Peterson \& McCabe 1991; Minami 2002; McCabe, Bailey, \& Melzi 2008; Miller, Koven, \& Lin 2011; Khimji \& Maunder 2012; Miller, Chen, \& Olivarez 2014). Whether a storyteller emphasizes the exploits of the individual in overcoming obstacles, elaborates the network of social and situational ties that undergird a particular happening, or adopts a more self-effacing and spare accounting of events depends, at least in part, on the cultural priorities of individuals and the communities in which they reside (Schick \& Melzi 2010). 
Though research has documented the ways that teachers from European American backgrounds can be unfamiliar with and unready for diverse ways of storying experience (Michaels 1981, 2006; Delpit 1995; Cazden 2001; Christie 2002), encouraging and capitalizing on children's prior experience with language offers rich potential for classroom learning. 'It is important to value a wide range of ways of using language at school, giving different languages, dialects, and ways of meaning more social value by having them shared in the schooling context' (Schleppegrell 2004:21). Variation in ways of meaning includes language that is spare and restrained (Minami 1996; Minami 2002), deeply descriptive (Jimenez-Silva \& McCabe 1996; Cheatham \& Jimenez-Silva 2011), exaggerative, playful, and entertaining (Champion 2003), language that relies on implicit or metaphoric relationships (Michaels 1981, 2006; Hyon \& Sulzby, 1994; Champion 2003), and even discourse that is co-constructed in an interactive back and forth (Au 1993).

\section{Ideational threads}

Storytelling is not just structurally patterned and sensitive to cultural priorities, it is also socially situated and fundamentally dialogic (Bakhtin \& Holquist 1981). Storytelling is a discursive act through which children construct ideational, social, and textual meanings (Halliday 1975), as they negotiate social realities and social spaces. Dialogic in nature, stories, like all language, presuppose earlier statements even as they anticipate future responses: 'The speaker talks with an expectation of a response, agreement, sympathy, objection, execution, and so forth' (Bakhtin \& Holquist 1981:69).

Ideational threads are the participants, processes, and circumstances which repeat across stories, demonstrating the way that ideas are introduced and continued through stories. Even 
young children have been shown to talk in 'rounds of stories' (Küntay \& Şenay 2003:560) in which stories respond to previous stories, telling about and extending an idea. Young children have been shown to engage in thematic emulation, in which they tell a story that repeats a prior story with little variation as well as thematic elaboration, which contains some repetition along with variation and elaboration (Küntay \& Şenay 2003). Through emulation and elaboration children co-construct larger conversations with thematic continuity, while simultaneously establishing the thematic relevance of their own contributions.

\section{Comments}

Ideational threads that reveal the thematic continuity, variation, and elaboration in children's stories make up but one way of negotiating group talk through story. Comments are another way that young children manage story as 'political activity' (Kyratzis 2000). Comments are an additional tactic that children employ to assert their power within the classroom and establish hierarchy within groups. Hierarchy can be established and maintained by preschool children through many different strategies including copying, excluding, one-upmanship, and seeking ratification from the group (Kyratzis 2000). So too, stories help children express affiliation, acting as a useful social tool for establishing alliances, cooperating, and coparticipating (Goodwin 1993; Kyratzis 2000). Comments help children achieve these goals as well.

Agentic language learning in multicultural preschool classrooms

This conception of story as carefully constructed patterns of culturally informed language which serve as a dialogic vehicle for navigating social life holds particular relevance for the growing number of early childhood multilingual classrooms. Multilingual peer groups offer 
critical support for language learning as children negotiate valued ways of making meaning together (Björk-Willén 2007; Cekaite \& Björk-Willén 2012; Gynne \& Bagga-Gupta 2013). As Dyson notes, 'School brings many children together in one space. And those children develop social bonds and playful practices linked to, but not controlled by, adults' (Dyson 2002:549).

The dialogic quality of storytelling offers rich potential for establishing greater child ownership over classroom discourse, disrupting traditional power dynamics that position the teacher as the sole architect of formal learning opportunities. Teachers have been shown to make better discursive sense with children who share the same cultural expectations for ways of using language (Michaels 1981, 2006; Heath 1983; Delpit 1995). In this way, issues of power are enacted in classrooms as particular linguistic forms and communicative strategies are elevated over others, forming the codes for participating in a culture of power (Delpit 1988).

An initiation into literacy requires children to not just passively receive prescribed norms, but to play a role in shaping discursive requirements of the communities to which they belong. Teachers have a vital role to maintain an 'interplay' between children's contributions and canonical forms (Delpit 1988, 1995; Cazden 2001; Bliss \& McCabe 2008). So too, a balance of rights (Cazden 2001) which allows for greater shared control over classroom discourse and the norms which dictate it offers a promising way to disrupt the limited, formulaic, and narrow discourse that characterizes too many formal learning opportunities in early childhood education.

\section{Theoretical orientation}

This study proceeds from a sociocultural perspective that recognizes that the learning of young children takes place in socially and culturally situated environments. Young children construct conceptual understanding, drawing on the unique contributions of prior experience, 
cultural background, and on-going interaction with multiple environments and learning partners (Vygotsky 1978). Though the role of the adult as a scaffold for young children's learning has been well documented, an often overlooked aspect of a sociocultural approach to learning is the capacity of children to support and shape one another's learning.

The current study leverages this capacity by setting up a small group storytelling activity called story circles as a way for children to work closely in small groups over the course of a four week period. Countering prevalent conceptions of lower SES children as lacking in relevant knowledge (see Dyson 2002 for discussion), story circles position children's ideas, feelings, and values as the driving engine for learning by asking the teacher to serve as a facilitator while children practice and model using language.

The social semiotic perspective of language as articulated by SFL (Halliday \& Matthiessen 2004) informs the analysis. Central to the SFL perspective is the conception of language as a meaning-making system through which individuals use choices in the grammar of language to construe experience. A significant goal of SFL is to make visible the way that meaning is made, with the potential to bring to consciousness the way that power can be constructed and continued through spoken and written texts (Christie 2013).

With this in mind, the current study asks:

What are the interactive features of small group storytelling?

What do these features suggest about the affordances and constraints of child-led storytelling activities in preschools serving lower SES, multicultural, and multilingual configurations of children? 


\section{METHODS}

Sample

This study took place in two urban preschools serving a multicultural, multilingual configuration of children. The preschools operated mixed-age, play-based preschool, using the Creative Curriculum (Teaching Strategies 2013) to guide ongoing, theme-based studies with children. In all, 49 children participated in the study. Though $67 \%$ of the children in the sample spoke a language other than English as the primary language in the home (per parent report), classroom instruction proceeded almost exclusively in English. Environmental print in the classroom reflected the multiple languages spoken by children with classroom areas labelled in English, Spanish, Ukrainian, and Arabic. Further, small subsets of children used Ukrainian or Spanish as their primary language during play.

The sample consisted of predominantly Latino (57\%) preschoolers, although six different, parent-reported, ethnic groups were represented in the classrooms, including European American (29\%), African American (4\%), Arab American (4\%), Asian American (4\%), and mixed ethnicity, African American \& Latino (2\%). Children in the sample ranged in age from 36 months to 64 months. The average age was 54.2 months $(\mathrm{SD}=6.8)$. Just under half the sample

were female (49\%). A portion of the children (16\%) had an Individualized Education Plan (IEP) in speech and language at the time of the study.

\section{Data collection}

Data was collected as part of a month-long participation in story circles. Story circles consisted of small groups of four or five children who met once a week to tell stories of their own choosing. Researchers divided the 49 children into ten story circle groups which met four 
times each for a total of 40 individual story circles in the study. Story circle groups were formed strategically with teachers, aiming to create groups that varied in terms of age, ability with language, and status as a monolingual or multilingual child. Mixed ability groups were formed to leverage children's capacity to support one another's learning. In a story circle, each child took a turn telling a story in response to the prompt: "This is a story circle. In a story circle you can tell a story about anything that you want". The same children met from week to week, alternating the order in which they told stories. All story circles were audio recorded, transcribed, and coded according to story genre, culturally shaped features of language use, ideational threads, and comments.

In the first week of the story circle, the facilitator told a brief narrative type story (see Text 1) as a model for children's participation. The example story intentionally modeled expectations of genre for narrative stories as described in SFL, including the use of a complication which lingered as the storyteller suspended the action with an explicit evaluation of events before bringing the complication to a resolution (Rothery \& Stenglin 1997). In this way, the story deals with and evaluates problems. Since story circles aim to elevate and amplify the voices of children, a facilitator example story was only told in the very first week of participation. All subsequent story circles began with a child storyteller.

\section{Text 1}

Facilitator Example Story

This is a story about when I was young.* Abstract

One time, I went hiking with my family on a mountain trail. Orientation Suddenly, when I put my foot down, it began to move in a Complication zigzag from side to side. 
I was so scared.

When I looked down I discovered that I had stepped on a small

snake. The snake's body moved in a zigzag on the trail, so my

foot moved that way too (moved hand in zigzag motion).

I lifted my foot and it slithered away.

But I was still so scared because I was afraid of snakes.

Nothing happened though.

The snake kept moving and I continued to walk with my family.

* Commas represent pauses. Periods represent full stops.
Evaluation

Events

Resolution

Evaluation

Resolution

Teacher models are one way that children can become more familiar with the discursive practices typically valued in schools as teachers aim to strike a balance between children's contributions and canonical forms, making space for children to navigate expectation and invention in their stories. Analysis

The analysis for this paper draws on a larger study of children's stories which used SFL (Halliday \& Matthiessen 2004) to parse stories, showing the connection between clause level ideas, story stages, story genres, and features of interaction (Flynn 2013). The analysis reported for this paper considers story genre and culturally shaped linguistic features of story, while primarily focusing on interactive features of storytelling like ideational threads and comments. Story genres

\begin{tabular}{|l|l|l|}
\hline One time, & I & went hiking \\
\hline Circumstance of Time & Actor & Doing Process \\
\hline
\end{tabular}


In this study, I used a genre-focused approach to analyzing young children's storytelling. I first analyzed children's stories as configurations of participants, processes, and circumstances. For example, consider the orientation of the facilitator story: "One time, I went hiking with my family on a mountain trail". The facilitator gave information about a participant who "went hiking” (process) with family (circumstance of accompaniment) on a mountain trail (circumstance of location) one time (circumstance of time).

\begin{tabular}{|l|l|}
\hline with my family & on a mountain trail. \\
\hline Circumstance of Accompaniment & Circumstance of Location \\
\hline
\end{tabular}

Then, I examined these configurations for known patterns of grammatical realization and functional purposes of story stages. For example, the facilitator oriented the listener to events, characterizing the experiential context (functional purpose) in terms of circumstances of time, location, and accompaniment (grammatical realization), making this an orientation stage.

After labeling each story in terms of story stages, I characterized each story in terms of distinct story types that unfold in different, prototypical ways: narrative, recount, or observation type stories. A family resemblance approach was employed such that children's stories were not expected to strictly adhere to a prototypical model so much as flexibly reflect the diverse ways to make meaning. Each story genre was determined based on the presence of a defining middle stage of story: complications for narratives, a series of events for recounts, and description and evaluation for observation. A thorough description of the coding of story genres is reported elsewhere (Flynn In press).

Culturally shaped features of story 
Culturally shaped features of storytelling include documented variations in storytelling style thought to be linked to the priorities of individuals and the communities in which they reside (Schick \& Melzi 2010). These priorities and accompanying ways of using language have been shaped by 'histories, patterns of face-to-face interactions, and ways of adjusting both to the external environment and to individuals within and outside their groups' (Heath 1983:11). All uses of language are culturally shaped. However, the culturally shaped features highlighted for this analysis include uses of language documented as prevalent in different types of discourse communities, but often unrecognized and undervalued in U.S. schooling.

Though a wide array of culturally shaped features of storytelling were considered in this analysis, in this paper, I report the features of storytelling that were prevalent in the sample. Culturally shaped features of storytelling documented in this study include the use of:

- topic associating with implicit or thematic links and temporally or spatially distinct contexts (Michaels 1981, 2006; Hyon \& Sulzby 1996; Cazden 2001; Champion 2003),

- stories of personal experience, punctuated by humor, joking, and teasing (Au 1993),

- emphasis on description, especially of seemingly tangentially related occurrences (JimenezSilva \& McCabe 1996; Cheatham \& Jimenez-Silva 2011),

- long, exaggerative, and humorous accounts (Champion 2003),

The prevalence of culturally shaped features of storytelling was determined by identifying and counting the number of stories which included culturally shaped features of storytelling.

\section{Ideational threads}

Ideational meanings are realized as language unfolds through configurations of participants, processes, and circumstances. Participants, processes, and circumstances make up 
ideational threads when they are continued from one story to another either in the same story circle or from week to week. Each participant, process, or circumstance which was repeated across stories was marked as an ideational thread. For example, the facilitator example story began with a circumstance of time:

when I was young.

Circumstance of Time

When a child's story began with a similar circumstance of time like:

When I was little,

Circumstance of Time

the stories were identified as having a shared ideational thread. The prevalence of ideational threads was determined by identifying shared ideas in each story circle group.

\section{Comments}

The second interactive feature of story circles employed by children was comments made before, during, and after story circle turns. Comments ranged from general interaction not directly related to the story circle like inviting a friend over to play to comments aimed at directing other children's storytelling in some way. Each comment was categorized according to the function the comment served in the story circle.

[Insert Table 1 here]

The prevalence of comments was determined by counting the number and types of comments made in story circles as well as considering the number of story circles in which comments occurred and under what conditions. 


\section{RESULTS}

The children in this sample told stories that varied in genre of story and use of culturally shaped features. These carefully constructed stories responded dialogically to one another, connected by shared ideational threads and negotiated through comments that encouraged and prescribed ways of telling stories in the story circle. The stories were inextricably linked to the context of the classroom, but reverberated with the echoes of extended networks of relationships and experiences in the home and community.

\section{Ideational threads in the story circle}

The children's stories directly responded to the existing classroom culture, the facilitator's example story, and to other children's stories. Through these responses, the children maintained an ever shifting dialogue of ideas, interests, and identities which their stories sustained and extended. In 35 out of the 40 story circle groups (88\%) at least two stories included a shared ideational thread. In some instances, children continued the same ideational thread from week to week. This shows how when the children in this sample were positioned to lead and shape the conversation, they made connections and built on one another's ideas. Instructionally valuable interactions occurred even without the teacher tightly controlling the conversation and agenda.

Furthermore, more than a quarter of the children's stories, 49 out of $176(28 \%)$, responded to the initial story example by relating a story about being young, being scared, or an encounter with a snake (see Text 1). In these stories, children picked up and extended an 
ideational thread like the circumstance of time, "when I was young," in many cases responding to an ideational meaning that already figured prominently in the classroom.

\section{Comments in the story circle}

Children's stories also shaped and were shaped by the story circle activity through direct comments made during participation. In half of the story circles, at least one child commented to another child before, during, or after a story turn. All ten of the story groups made comments at one time across the four weeks of the activity. Table 2 shows the frequency of different types of comments made in the story circle.

\section{[Insert Table 2]}

The children in this sample were largely responsive to the input of classmates. The majority of children's comments aimed to prescribe some aspect of other children's storytelling. All 20 story circles that included a comment contained remarks about what a particular storyteller should do - they should speak louder; they should end this story; they should tell a different story; or they should start or end their story like this. In this way, children in these story circles made direct statements about what stories should be like, and their circle-mates typically responded by speaking louder, ending their story, telling a different story, or even beginning their story in a particular way. However, children did not just passively receive and accept feedback on their storytelling. Instead, at times, children disregarded a comment, made comments on other children's storytelling in return, or commented in following weeks as a way of having an equal say on how the story circle unfolded.

Genres, culture, and dialogue in a story circle 
Examining the interaction of three children highlights the complexity of children's endeavors to make meaning in a story circle context. Ultimately, to be literate is to play a role in negotiating what constitutes valuable ways of making meaning as language and literacy are discursive practices in which contesting ideas, ways of being, and even ways of meaning are mediated. In this respect, the interactions of three young children highlight what an initiation to literacy might look like when children are positioned to author not just their own story, but the way that storying unfolds in the classroom.

At the time of the study, the children in this example were learning about the life cycle of butterflies in their classroom. Also during the study, three mothers in this classroom were pregnant. As a result, the teachers and children in this classroom discussed growing and changing as part of their regular instructional activities. In this respect, the children's stories responded not just to the facilitator example story and its ideational thread about 'being young,' but to the larger ongoing study of the classroom context with its focus on babies, growing, and what different points in the lifespan are like.

Nested in this classroom context, Maricruz, Carlos, and Diamond exchanged stories about being young, establishing points of connection and departure. At the time of the study, Maricruz was four years and one month old, a Latina whose home language was Spanish. Carlos was five years and two months old. He was Latino and spoke Spanish as his primary language in the home. Diamond was five years and one month old, an African American who spoke English as her primary language in the home. In the text below, ideational threads that occurred in the context of this story circle group are highlighted in bold. The ideational threads included 
participants, processes, and circumstances which occurred across stories in the circle and will be discussed below.

\section{Text 2}

Story Circle Interaction

Maricruz Whe, when I was a, a little girl. I, I would go to the park with my daddy and my sister. And then, a, a my doggie. Ah, a there were. He was geing to go. Ah, on the slide. But I would not let him go. I'm finistred

Ideational Thread:

Carlos When I was a little baby (laughs), I was la da da (laughs). And I was do do to lo do da (laughs). Then I was raaaaaa (raises voice, leans back head, and lets out State of loud cry). And my papi say "brrr brrr brrr" (making Being Little mock talking sound and shaking finger in a scolding fashion).

Diamond And that's it.

Carlos

Diamond Um I was um, one. I went to school. I went to school, And I eat all my milk. And go in my pants. And be a baby with my dad. The lend. and they learned. They helped me to learn. And um, my mommy helped. My mommy helped me. My mommy hold my bottle. And, um, (looks at facilitator). Give me a minute to think (taps finger on face just above lip). Hmmm.

Carlos (taps finger just above lips and laughs) 
Diamond And then she put me to sleep. And when I woke up, it was still dark. I went, "Huh" (hands on hips, widens eyes). "Why is it still dark." And um then, I went, "Mommy, mommy. It's still dark and it's morning time. What's going on. Um, I think the lights have been shut off on me there." "Whaaat." I went, "Whaaat." I went "Yeah, it's like shut off some of the earth. It's like 2 o'clock. Come on. You got to be kidding me. And I went (hands on hips, leans forward) "Hey. What the big idea." Then I found the guy that made the, made the earth. I went "Come on. What's the big idea. Why are the lights turned off. It's morning." But it's six o'clock. And it's two thirty. "Come on."

Carlos Waaa. Waaa. Waaa. (starts shaking up and down while squeezing hands together)

Diamond Why is my shirt wet (reaches down and touches bottom of shirt). And, um, hmmm (puts finger up to lips). And um, I was. I was two. Then it was my birthday. And I had um. Um, America, America rock. America rattle. And um, and I had a dress with white and um orange. Purple. Um, and I had a birthday hat. And there was like red lines sticking out of my dress. My daddy and my mommy were there. We were at our old house. It was really high. At fifth, the. We took an elevator to second. To the third floor. And um. And we went in the house and played. We went in the house and played. Twister. Then we sit. We were sitting. Watching a movie. And drinking hot coco. And um, I was. And then I go three.

Carlos The end. The end. The end.

Diamond And then we still played. And then, I still drink bottles. Then the end.

In this story circle interaction, the children told different genres of story and included what are thought to be culturally-shaped features of storytelling. Maricruz, the youngest of the three, told a simple narrative story with the beginnings of the signature complication and resolution stages as understood in SFL. An unusual or problematic event was anticipated when 
her dog "was going to go. Ah, on the slide." This anticipated complication was resolved when Maricruz prevented the dog from doing so. In this respect, Maricruz successfully introduced a moment of counter expectancy and a return to the usual, though she construed this not in terms of a past series of events so much as a possible complication which was forestalled.

Even in this simple account, Maricruz construed experience with a budding sophistication that reveals the value of intentionally making space for child-led discourse. Her story unfolded in waves of information, carefully constructed configurations of participants, processes, and circumstances that communicate happenings experienced both internally and in the world (Halliday 1975).

\section{Text 3}

\section{Whe, when I was a, a little girl.}

Circumstance of Time

\begin{tabular}{|l|l|l|l|}
\hline I, I & would go & to the park & with my daddy and my sister. \\
\hline Actor & Doing Process & Circumstance of Location & Circumstance of Accompaniment \\
\hline
\end{tabular}

\begin{tabular}{|l|l|}
\hline And then, & a, a my doggie. \\
\hline & \\
\hline
\end{tabular}

\begin{tabular}{|l|l|}
\hline Ah, a there & were. \\
\hline & \\
\hline
\end{tabular}

\begin{tabular}{|l|l|l} 
He & was going to go. & Ah, on the slide.
\end{tabular}




\begin{tabular}{|l|l|l|}
\hline Actor & Doing Process & Circumstance of Location \\
\hline
\end{tabular}

\begin{tabular}{|l|l|l|l|l|}
\hline But & I & would not let & him & go. \\
\hline & Agent & Causing Process & Actor & Doing Process \\
\hline
\end{tabular}

\begin{tabular}{|l|l|}
\hline I & 'm finished. \\
\hline Actor & Doing Process \\
\hline
\end{tabular}

These waves of information unfold in a simplified version of a now well known pattern, or genre, used when individuals story experience - a narrative story.

Genres of story are realized through both the functional purpose and grammatical realization of different stages of story. Maricruz oriented the listener to events, characterizing the experiential context (functional purpose) in terms of circumstances of time, location, and accompaniment, while using a multi-clause structure frequently featured in story orientations (grammatical realization).

Whe, when I was a, a little girl. I, I would go to the park with Orientation my daddy and my sister.

After a couple false starts, Maricruz then introduced a complication to her story, disrupting the flow of events with an unexpected or problematic event (functional purpose). She construed the potentiality of the complicating event through the doing process, "was going to go" (grammatical realization).

And then, a, a my doggie. There were. He was going to go. Ah, Complication on the slide. 
Maricruz restored events to usuality (functional purpose) with a resolution, realized through a conjunction of contrast, a causative doing process, and changing participant roles in which the active participant shifted from the dog to Maricruz (grammatical realization). Conjunctions of contrast and shifting participant roles are both commonly employed features of story resolutions.

But I would not let him go. Resolution Maricruz brought her story to a conclusion through a direct statement of conclusion.

I'm finished. Statement of Conclusion She produced a simple, but complete narrative story. In Maricruz's story, valued ways of construing experience are practiced and modeled for other children in ways that are reminiscent of more mature storytelling performance, but may not always be immediately apparent.

In this simple instantiation of a narrative story, Maricruz continued a number of ideational threads from the facilitator story and larger classroom context. She echoed the idea of 'being young' while introducing the park and slide as significant locations and her dad, sister, and dog as important participants in experience. Structurally, Maricruz's story mirrored the element of counter expectancy typical in narrative stories like the facilitator story, connecting to the previous story by telling about a time when something unexpected happened.

Carlos followed Maricruz's story with a different genre of story, a recount story which unfolded as a series of events and a reorientation which returned the listener to the experiential starting point. 


\section{Text 4}

When I was a little baby (laughs), I was la da da (laughs). Orientation

And I was do do lo lo do da (laughs). Events

Then I was raaaaaa (raises voice, leans back head, and lets out loud cry).

And my papi say "brrr brrr brrr" (making mock talking sound and shaking finger in a scolding fashion).

And I eat all my milk.

And go in my pants.

And be a baby with my dad. Reorientation

$\begin{array}{ll}\text { The end. } & \text { Statement of Conclusion }\end{array}$

Recount stories like Carlos' unfold as a series of events, often signaled through the use of additive and temporal conjunctions like 'and' and 'then' as well as the use of doing processes through which experience is construed as a series of actions. In this story, Carlos cried, the father scolded, Carlos drank all his milk, and he went to the bathroom in his pants.

Carlos used a simple, but sophisticated ending stage to reinforce the meaning of his story. The literal repetition of language which establishes Carlos as in a state of being a baby in the orientation and then at the end of the story in the reorientation gives the story a sense of circularity, at once returning the listener to the experiential starting place of the story and reinforcing the story's overarching meaning - a recounting of what it is like to be a baby. In the end, the story is not just about when Carlos "was a little baby," but about being a little baby 
"with my dad" as Carlos extended the idea introduced in the orientation of the story to signal his dad as significant participant with a circumstance of accompaniment.

Carlos used expressive language, mimicking crying and scolding to give a more evocative portrayal, using sound as a metaphor for action. He shook his finger in mock scolding fashion so that his audience could not just hear, but see the recounted events. Such an evocative, performative storying of experience is common amongst many cultural groups with oral storytelling traditions (Champion 2003). Though not typically explicitly taught in schools, expressive renditions like Carlos' are highly effective ways to communicate experience in ways that compel and capture an audience. Though previous research shows that young children are highly attentive to adult listeners as important audience members (Küntay \& Şenay 2003), Carlos clearly makes a bid to entertain and interest the children in the story circle.

Carlos practiced and modeled a different genre of story than Maricruz and introduced evocative language and gesture, but still echoed Maricruz's story in important ways. Structurally, each child began their story with a similar multi-clause construction. Maricruz began her story:

\begin{tabular}{|l|l|}
\hline Whe, when I was a, a little girl. & I, I would go to the park with my daddy and my sister. \\
\hline Dependent Clause & Independent Clause \\
\hline
\end{tabular}

Carlos used a parallel construction for his story orientation:

\begin{tabular}{|l|l|}
\hline When I was a little baby (laughs), & I was la da da (laughs). \\
\hline Dependent Clause & Independent Clause \\
\hline
\end{tabular}

In the orientation, Carlos continued the ideational thread about being little, refining the idea to be about being a baby, an important idea in the classroom at the time. Carlos also continued 
Maricruz's introduction of "my daddy" as a significant accompanying participant, using the Spanish designation "papi" and later "my dad" to extend the thread. Using sound as a metaphor for action, Carlos introduced the ideational threads of crying - "I was raaaaaa (raises voice, leans back head, and lets out loud cry)' - and scolding - 'my papi say "brrr brrr brrr" (making mock talking sound and shaking finger in a scolding fashion).”

Diamond continued this expressive turn, telling a long, entertaining, exaggerated, and structurally complex narrative story reminiscent of African American storytelling styles (Champion 2003). Diamond structured her story into a series of events which occurred during each year of her life - "I was um, one," "I was two," and "and then I go three." For each year of her life, she oriented the listener to a new time and location, a feature of storytelling reminiscent of topic associating storytelling, a storytelling discourse pattern documented amongst African American speakers (Michaels 1981, 2006; Cazden 2001). In topic associating storytelling, children tell stories about seemingly contextually distinct occurrences or episodes which are often united by an implicit or metaphorically related theme. In this case, Diamond has elaborated on the ideational thread of being little. She used a series of orientations to introduce each episode associated with each year of her life.

\section{Text 5}

Um I was um, one. I went to school. Orientation

I went to school, and they learned. Events

They helped me to learn.

And um, my mommy helped. My mommy helped me.

My mommy hold my bottle. 
And, um, (looks at facilitator). Give me a minute to think (taps Interactional Aside finger on face just above lip). Hmmm.

(Carlos taps finger just above lips and laughs)

And then she put me to sleep.

Event

And when I woke up, it was still dark.

Complication

I went, "Huh" (hands on hips, widens eyes).

Evaluation

"Why is it still dark."

And um then, I went, "Mommy, mommy. It's still dark and it's

morning time. What's going on. Um, I think the lights have

been shut off on me there."

"Whaaat." I went, "Whaaat."

I went "Yeah, it's like shut off some of the earth. It's like 2

o'clock. Come on. You got to be kidding me.

And I went (hands on hips, leans forward) "Hey. What the big idea."

Then I found the guy that made the, made the earth.

Resolution

I went "Come on. What's the big idea. Why are the lights turned Evaluation

off. It's morning."

But it's six o'clock. And it's two thirty.

"Come on."

C: Waaa. Waaa. Waaa. (starts shaking up and down while

Interactional Aside

squeezing hands together)

D: Why is my shirt wet (reaches down and touches bottom of shirt). And, um, hmmm (puts finger up to lips).

And um, I was. I was two. Then it was my birthday.

Orientation 
And I had um. Um, America, America rock. America rattle. Description

And um, and I had a dress with white and um orange. Purple.

Um, and I had a birthday hat.

And there was like red lines sticking out of my dress.

My daddy and my mommy were there.

We were at our old house.

It was really high. At fifth, the.

We took an elevator to second. To the third floor. Events

And um. And we went in the house and played.

We went in the house and played. Twister.

Then we sit.

We were sitting.

Watching a movie.

And drinking hot coco.

And um, I was. And then I go three.

Orientation

C: The end. The end. The end.

Interactional Aside

And then we still played.

Events

And then, I still drink bottles.

Then the end.

Statement of Conclusion

In terms of genre, Diamond's story drew on defining features of narrative type stories: 1) introducing an unexpected or complicating event; 2) extending the suspense through an evaluative stage that provides an interpersonal take by communicating attitudes, opinions, or indicating the usuality of events; and 3) resolving events by bringing about a return to the status quo or the typical. Diamond's story of the first year of her life consists of relatively mundane 
events punctuated by an extended evaluative moment which culminates in her questioning "the guy that made the, made the earth." This is a bold proclamation of power. One that is unlikely to be teacher modeled or adult sanctioned.

Diamond's story drew important connections to the other stories in the story circle.

Structurally, the topic associating style of Diamond's story resulted in three distinct episodes, the first of which used the counter expectancy of narrative like Maricruz's story about her dog going on the slide. The second episode had an extended description that sets the scene for a recounting of her birthday which unfolded as a series of events not unlike the structure of Carlos' recount story about being a baby.

Diamond continued the overarching thread about being little, but without the multi-clause orientation that began, "When I was a little . . .." Instead, Diamond's story is more specific and elaborated, attempting to tell about each year of her life leading up to the present. Diamond continued the earlier thread about family members as significant participants, this time introducing her mother. Diamond responded to Carlos' story about being "a baby with my dad" by telling about how when she was one, "My mommy helped me. My mommy hold my bottle." Like Maricruz and Carlos, Diamond introduced new ideational threads which were continued throughout the story circles: playing, birthdays, and hot cocoa.

In this story circle, children's seemingly simple stories deploy language in distinct patterns or genres of story with valued culturally shaped features that are routinely part of discourse practices in the home and community, but rarely practiced, taught, or valued in school settings. But the children's stories are not simply 'artifacts' of interaction 'abstracted from their local circumstances' (Goodwin 1993:110). Instead, each story responded to and advanced ideas 
which run like threads through the children's stories, helping the children to achieve 'thematic relevance' by emulating and varying a theme (Küntay \& Şenay 2003:564).

The children also played a role in shaping the story circle activity, commenting as a way to have a say in the activity. Throughout the exchange, Carlos and Diamond interacted, intervening in one another's storytelling. Diamond began by commenting, "and that's it," as Carlos recounted his experience as a baby. Carlos playfully joined Diamond in her expressive show of thinking, tapping his finger just above his lip after she did and laughing. Later, after an extended account of it being "still dark and it's morning time," Carlos began shaking and exclaiming, "Waaa. Waaa. Waaa," in an exaggerated show of impatience, almost as if he might explode if Diamond continued. Diamond was briefly distracted, noticing her wet shirt, before continuing the story undeterred. After recounting what happened when she was one year old, she began to tell about her experience when she was two. When Diamond began telling about her experience at age three, Carlos exclaimed, "The end. The end. The end," in rapid succession. This time Diamond responded to Carlos' attempts to end her storytelling, offering two more events before concluding.

Carlos' intervention suggests it is appropriate to tell about when you are little, but not to recount each year of your life leading up to the present. Carlos' use of the common story ending, "the end," as a way to conclude Diamond's storytelling was in keeping with other instances in which a child told an unusually long story. On several occasions, other children commented, "the end," when the long story lost focus or seemed likely to continue for an additional extended period. In this way, children used their interjections as a way to help establish norms for storytelling in the story circle with one norm being a tacit consensus about appropriate length. 
In their next story circle, the children continued ideational threads from the previous

circle and introduced new ideas. Maricruz, who just moments before the story circle had become sick, began the circle with a short story which continued with her dog as a significant participant and the park as the location of events.

\section{Text 6}

Following Week Story Circle Interaction

Maricruz (Coughs) I was. Me and my doggy. Were playing in the park. And then my mommy said. "It's time to go."

Carlos The end.

Maricruz The end.

Diamond Um, when I was a little girl. Blah, blah, blah, blah. When I was a little girl, um. I liked to play with my mom in the snow. We made a snowman and a snow angel. And, um, and we went inside to get hot cocoa. And um, then we went to Enchanted Castle to play. When it was my birthday. And um, we were playing a new game at Enchanted Castle. It was good. But they didn't tell us what the name was. And then, they gave me a tattoo. Um, a castle one. A princess. They gave me a lot. And um, then. Then, there was a slide that had a lot of water. It was really long. It was called a tube slide. It was cool. And then, we went to Key Lime Cove and played. The end.

Facilitator (Diamond stands up to leave.) Diamond, stay here please. Until Carlos finishes his turn. (Diamond sits down again.)

Carlos When I was a little boy. Um, my daddy has a long, a long, a long hair. And I saw that in the picture. And they give me all, a lot of toys. And then, he say "Ah, good boy." And the puppy say "Ahbbabbabaa maah." And eat the bone. Me say "Wahh wahh wahh wahwowowo." And dad says "No. Don't. Go. Do. That." The end.

In this story circle turn, all three children told recount genre stories which unfolded as a series of events. Maricruz adopted Diamond's and Carlos' style of using reported speech in the 
story as the listener can hear the mother call out, "It's time to go." This shows how children can serve as models for one another, demonstrating skillful ways of storying experience. So too, repeated engagement in a storytelling activity offers children an opportunity to try out different ways of relaying events.

\section{Text 7}

I was. Me and my doggy. Were playing in the park. And then my mommy said. "It's time to go." C: "The end."

The end.

\section{Orientation}

Event

Interactional Aside

Statement of Conclusion

Maricruz concluded her story with the natural concluding event of it being "time to go." The previous week the children established the convention of ending their stories with an explicit statement of conclusion, which Maricruz omitted in this storytelling turn, prompting Carlos to state, "the end." Maricruz echoed Carlos' statement, complying with and reinforcing the convention of an explicitly stated ending.

In terms of ideas, Maricruz built on her story from the previous week, continuing the same circumstance of location and significant participants. She extended the overarching thread of naming family members as important participants. She began the story with herself and her dog as the two active participants and then concluded the story with her mother, a significant participant introduced the previous week in Diamond's story. She continued Diamond's idea of play as a central activity while continuing her own ideational thread from the previous week about the park. 
Diamond's story responded to Maricruz's story about play, employing a topic associating style, shifting spatial and temporal locations as an implicit theme was explored, in this case playing at different places. The story began with an account of Diamond playing with her mom in the snow,

When I was a little girl, um.

Circumstance of Time

\begin{tabular}{|l|l|l|l|l|}
\hline I & liked & to play & with my mom & in the snow. \\
\hline Actor & $\begin{array}{l}\text { Sensing } \\
\text { Process }\end{array}$ & Doing Process & $\begin{array}{l}\text { Circumstance of } \\
\text { Accompaniment }\end{array}$ & $\begin{array}{l}\text { Circumstance of } \\
\text { Location }\end{array}$ \\
\hline
\end{tabular}

shifted to playing at Enchanted Castle when it was her birthday,

\begin{tabular}{|l|l|l|l|l|}
\hline And um, then & we & went & to Enchanted Castle & to play. \\
& Actor & Doing Process ... & Circumstance of Location & $\ldots$. . Doing Process \\
\hline
\end{tabular}

When it was my birthday.

Circumstance of Time

and concluded with going to the water park Key Lime Cove.

\begin{tabular}{|l|l|l|l|l|l|}
\hline And then, & we & went & to Key Lime Cove & and & played. \\
\hline & Actor & $\begin{array}{l}\text { Doing } \\
\text { Process }\end{array}$ & Circumstance of Location & & Doing Process \\
\hline
\end{tabular}

In each orientation, the doing process of playing was repeated and a new circumstance of location and time introduced. 
In terms of genre, Diamond's story unfolded as a series of events in contrast to her previous story with the counter expectancy of a complicating event - the signature stage of narrative genre stories. On this occasion, she told a recount type story with a topic associating style.

\section{Text 8}

Um, when I was a little girl. Blah, blah, blah, blah. Orientation When I was a little girl, um. I liked to play with my mom in the snow.

We made a snowman and a snow angel.

Events

And, um, and we went inside to get hot cocoa.

And um, then we went to Enchanted Castle to play. Orientation

When it was my birthday.

And um, we were playing a new game at Enchanted Castle. Event

It was good. Evaluation

But they didn't tell us what the name was. Events

And then, they gave me a tattoo. Um, a castle one. A princess.

They gave me a lot.

And um, then. Then, there was a slide that had a lot of water. Description It was really long.

It was called a tube slide.

It was cool.

Evaluation

And then, we went to Key Lime Cove and played. Orientation

$\begin{array}{ll}\text { The end. } & \text { Statement of Conclusion }\end{array}$

Diamond continued several elements of her previous story by telling a story that included a series of temporally and spatially distinct episodes, providing description, and making explicit 
statements of evaluation, aspects of storytelling largely absent from Carlos' and Maricruz's stories.

Diamond's story echoed previous stories from the circle in important ways. She adopted the clausal structure and ideational thread used by Carlos and Maricruz the previous week. First, in a kind of false start and comment in which she said, "Blah, blah, blah, blah," in place of the independent clause.

\begin{tabular}{|l|l|}
\hline Um, when I was a little girl. & Blah, blah, blah, blah. \\
\hline Dependent Clause & Independent Clause \\
\hline
\end{tabular}

Then, she used the clausal structure as an orientation to the story.

\begin{tabular}{|l|l|}
\hline When I was a little girl, um. & I liked to play with my mom in the snow. \\
\hline Dependent Clause & Independent Clause \\
\hline
\end{tabular}

In this orientation, Diamond employed the exact language Maricruz had the previous week in her story about the dog trying to go on the slide by orienting the listener to a time when she was a little girl.

In her second storytelling turn, Diamond repeated several ideational threads from her own storytelling while also sustaining ideas introduced by her story circle mates the previous week. Diamond continued several of the ideational threads she introduced the previous week, again telling a story about playing, being with her mom, drinking hot cocoa, and having a birthday. She told about a slide as Maricruz had the previous week, only this time a slide "that had a lot of water," an important variation on an already established idea. Finally, she introduced an ideational thread of being given "a lot," a new idea for this story circle group, but a common 
idea across the story circles in which the children frequently made self-aggrandizing statements about how much they had, especially how many toys they possessed.

In response, Carlos told another recount genre story which unfolded as a series of events.

\section{Text 9}

When I was a little boy. Um, my daddy has a long, a long, a Orientation long hair. And I saw that in the picture.

And they give me all, a lot of toys. Events

And then, he say "Ah, good boy."

And the puppy say "Ahbbabbabaa maah."

And eat the bone.

Me say "Wahh wahh wahh wahwowowo."

And dad says “No. Don't. Go. Do. That.”

The end.

Statement of Conclusion

He continued his more evocative storytelling style, dramatically crying. He mimicked the sound of a barking dog, a favorite sound which he frequently made in the classroom during play.

Finally, he revisited the idea of a father scolding. This time using short, clipped speech to emphasize each word. In contrast, to previous stories told in the circle, Carlos' story unfolded almost exclusively through reported speech as he recounted being a little boy through what was seen and said.

Though each story is distinct from one another and from the previous week's stories, the children continued ideas which ran like threads throughout the stories, connecting them in a larger dialogue. Similar to Maricruz and Diamond, Carlos told a story which directly responded to his own story the previous week, returning to several central ideas like being little, crying, 
scolding, and being with his dad. Carlos' story also directly responded to Maricruz's and Diamond's stories as Carlos echoed Diamond's claim about being given a lot and included a dog as an important participant in his story. Importantly, though Maricruz's stories are shorter and less embellished than her classmates, she still made an important contribution to the group. The children drew on her ideas as much as she drew on theirs.

In terms of comments, the group continued to intervene in each other's stories. This time, when Maricruz paused after saying, "It's time to go," Carlos said, "The end." Maricruz, then, said, "The end," formally concluding her turn. Diamond began her story saying, "Um, when I was a little girl. Blah, blah, blah, blah.” Perhaps, commenting on or resisting the activity, or tiring of the formulaic convention for beginning stories that the trio repeatedly used. After telling her story, Diamond rose to leave the circle before the facilitator told her to wait to hear Carlos' story, perhaps continuing the back-and-forth begun the previous week when Diamond and Carlos both interjected during each other's storytelling. If Carlos was not a patient listener for her story the previous week, why should she be an attentive listener for his?

In all, examining children's participation in story circles shows how when young children are given the space to author their own experience, the activity can be both collaborative and contested: children continue and reinforce particular ideas; they model and try out different ways of storytelling; but, they also intervene in and forestall other ways of participating.

The participation of Maricruz, Carlos, and Diamond shows the way that storying experience can be performative and value-laden, an expressive vehicle for identity, belonging, and the advancement of ideas. Maricruz's quiet, simple accounts about playing with her dog and family in the park show how the seemingly simple take on significance. She clearly shows how 
she is connected to family, but also to classmates who share an appreciation for playing, family, and pets. Carlos plays the role of entertainer, seeking to engage as he reminiscences about his connection to his papi, a connection that began when he was a baby, doing babylike things. Diamond connects to her classmates as she expresses her power as a girl with important experiences with family, who talks to the man who made the earth, and has "a lot." From princess tattoos, to birthday dresses, to the game of twister, Diamond has it. She is eager to hold the floor and let other children know.

\section{DISCUSSION}

Proceeding from a sociocultural perspective, this study asks: What are the interactive features of small group storytelling? What do these features suggest about the affordances and constraints of child-led storytelling activities in preschools serving lower socioeconomic status, multicultural, and multilingual configurations of children?

Story circles in this sample of children occasioned both the beginnings of canonical instantiations of story and discursive alternatives which often go unrecognized and under appreciated. The children told and heard different genres of story like recount stories which unfold as a series of events or narratives in which experience unfolded as complications to be resolved. The children in this sample also employed culturally shaped features of story, trying out discursive alternatives. For instance, Maricruz told stories that were short and to the point. Carlos told equally brief stories that were highly evocative, using sound as a metaphor for action. Diamond told longer, at times exaggerated, topic associating stories common amongst African American speakers. Unlike more teacher dictated opportunities for language use, the primarily 
child-led story circle opportunity allowed these different ways of storying experience to stand in conversation with one another as valid options for accounting for experience.

Through these diverse forms of story, the children in this sample maintained a dialogue in story. The children linked to and built on one another's stories through ideational threads which maintained shared ideas in the story circle from story to story and week to week. The children also used comments to encourage and direct one another's storytelling activity. In this way, the children established norms for what constituted valuable ways of participating in story circles. This is an important departure from solely teacher-shaped discursive turns, a departure which counters deficit conceptions of young children, especially multilingual, lower SES children. Instead, the children in this sample were far more agentic than is often reflected in routine classroom instruction, which rarely invites young children to lead or shape classroom conversations (Cazden 2001).

Examining one story circle group shows how children maintained and extended ideational threads which were drawn from the facilitator example story, from ongoing classroom interests, and from other children's stories. In this respect, the children's storytelling was deeply rooted in the context in which it occurred, but echoed children's larger worlds with family and in community as children maintained ideational threads about those they were in relationship with, places they went, and meaningful activities like sharing cocoa or being a baby with papi.

From this shared context, the children used stories about being young to present different aspects of the self, establishing a connection with circle-mates over a shared value placed on being with family and shared experiences such as playing at the park. The connections children established through story show how drawing on common values and experiences in the story 
circle provided a support for storytelling because children did not need to invent stories. They could draw on the common social fabric of their classroom culture. The connections did not just facilitate storytelling, but made storytelling a vehicle through which children could express identity and establish belongingness to the broader classroom culture. Research shows that some ways of using language and some identities are privileged in the classroom to the exclusion and marginalization of other ways of saying, doing, and being (Michaels 1981, 2006; Heath 1983; Delpit 1995; Cazden 2001; Christie 2002; Schleppegrell 2004). In this sample of children, story circles created a space for children to work together to decide what constituted valuable ways to say and do and be in the world.

The interactive features of storytelling, in this sample of children, also reveal several moments of real tension that arise when young children engage in 'complex interactive and interpretive processes' (Michaels 2005:113) in a reoccurring situation like story circles. Empowering children allows children to struggle with power, figuring out what it means to be authorial, what it means to be a fully participating member of a discourse community, what it means to negotiate ways of valuing amongst peers. Shifting the power dynamic away from an authorial teacher to nurture linguistically powerful children does not neatly resolve the dilemma that some forms of meaning making are privileged over others in school settings (Michaels 1981, 2006; Heath 1983; Delpit 1995; Cazden 2001; Christie 2002; Schleppegrell, 2004). In the absence of an evaluating teacher, the children seek to intervene, shape, and own the space, engaging in evaluation themselves, not unlike the 'political activity' documented in children's use of story in informal interactions in the classroom (Kyratzis 2000; Küntay \& Şenay 2003) and in community (Goodwin 1993). This leads to a departure from the cooperative classrooms that 
early childhood spaces often strive to be, but it immerses children in complex social spaces which language and literacy are used to navigate not just in school settings, but in the wider world (Goodwin 1993).

Through their participation, children shaped the storytelling activity and the culture of the classroom. They critiqued stories and aspects of performance, establishing literate identities as individuals who debate, value, and promote different ways of construing experience. Inevitably, the contested nature of what constitutes a good story rose to the surface. With the emergence of this core dilemma of literacy - what is valued, by whom, for what purposes - came conflict through the form of comments on other children's participation. I argue that there is real value to helping children navigate this core dilemma since it reflects literacy's status as an instrument of power and prepares children to assert and defend the power of their own ways of using language. However, open conflict of the kind generated by one child attempting to end another child's storytelling turn poses problems for teachers and threatens the imperative to maintain a classroom dialogue in which all children's voices are heard. In the classroom contexts studied here, children's engagement in a small group storytelling activity aimed at empowering children as authors of their own experience thrust the facilitator squarely into the heart of the very problem this study aims to address - the forms that language take in construing experience are recognized and valued differently (Michaels 1981; 2006; Heath 1983; Cazden 2001; Christie 2002). Some stories are valued while others are mischaracterized and marginalized as are the experiences of the individuals who tell these stories.

Shifting the power of authorship to children does not resolve the problems that arise from literate individuals evaluating, valuing, and promoting different ways of construing meaning. It 
does, however, make this dilemma salient in a way that it may not be for teachers who typically do the evaluating, valuing, and promoting as part of an unexamined and unproblematic practice of teaching ways of using language and literacy to mean.

Instead, teachers will be forced to weigh the value of cultivating children's capacity to respond to stories and to navigate a way forward with children as a community of learners. Just as there is a need for an interplay between children's contributions and canonical forms (Delpit 1988, 1995; Cazden 2001; Bliss \& McCabe 2008), a balance must be struck between the extent to which the teacher and the children shape and have ownership over the storytelling activity if the value of children assuming an authorial role is to be realized.

For example, when Carlos responded to Maricruz's natural ending (the mother announcing it is time to go), should the teacher intervene? Stories don't require an explicitly stated end like the children in this group preferred. Natural endings like the day ending or returning home have been documented as a storytelling convention amongst not just children, but adults (Hasan 1984). On the other hand, there is value to children developing classroom conventions together and discarding them when they no longer suit.

Opening spaces for children to assume power in the classroom, not just having opportunities to talk in extended turns, but to play a role in determining how such opportunities routinely unfold, does not undo the thorny issues of power that have been shown to arise in classrooms. Instead, it reveals just how complex and ever present power can be, even when young children marshal the resources of language to mean.

It may be that complex situations are just what the field of early childhood needs, because the complexity is a much better reflection of what it means to be literate, especially in diverse 
societies in which valued ways of saying, being, and doing are contested. An initiation into literacy is an introduction into expressing and contesting value. Child-led discourse simply shifts children's relationship to the process of being and becoming a literate member of the larger social world. The children advance ideas, build connections, and evaluate what constitutes valuable participation. The teacher's role is to listen. 


\section{REFERENCES}

Au, Kathryn H. (1993). Literacy instruction in multicultural settings. Fort Worth, TX: Harcourt Brace Jovanovich.

Flynn, Erin E. (2013). What story circles reveal about preschool children's storytelling.

Dissertation retrieved at http://deepblue.lib.umich.edu/bitstream/handle/2027.42/102401/ erinfly 1. pdf? sequence $=1$.

Flynn, Erin E. (In press). Storying experience: Young children's early use of story genres. Text and Talk.

Bakhtin, Mikhail M., \& Holquist, M. (Trans.) (1981). The dialogic imagination: Four essays. Austin: University of Texas Press.

Björk-Willén, Polly (2007). Participation in multilingual preschool play: Shadowing and crossing as interactional resources. Journal of Pragmatics 39:2133-2158.

Bliss, Lynn S., \& McCabe, Allyssa (2008). Personal narratives: Cultural differences and clinical implications. Topics in Language Disorders 28(2):162-177.

Cazden, Courtney B. (2001). Classroom discourse: The language of teaching and learning. Portsmouth, NH: Heinemann.

Cekaite, Asta \& Björk-Willén, Polly (2012). Peer group interactions in multilingual educational settings: Co-constructing social order and norms for language use. International Journal of Bilingualism 17(2):174-188.

Champion, Tempii B., Katz, Laurie, Muldrow, Ramona, \& Dail, Rochelle (1999). Storytelling and story making in an urban preschool classroom: Building bridges from home to school culture. Topics in Language Disorders 19(3):52-67. 
Champion, Tempii B. (2003). Understanding storytelling among African American children: A journey from Africa to America. Lawrence Erlbaum Associates.

Cheatham, Gregory A. \& Jimenez-Silva, Margarita (2011). What makes a good story?:Supporting oral narratives of young children from culturally and linguistically diverse backgrounds. Childhood Education 87(4):261-268.

Christie, Frances (2002). Classroom discourse analysis: A functional perspective. New York: Continuum.

Frances Christie (2013). Genres and genre theory: A response to Michael Rosen. Changing English 20(1):11-22. doi: 10.1080/1358684X.2012.757056.

Delpit, Lisa (1988). The silenced dialogue: Power and pedagogy in educating other people's children. Harvard Educational Review 58:280-298.

Delpit, Lisa (1995). Other people's children: Cultural conflict in the classroom. New York: The New Press.

Dickinson, David K. (2011). Teachers' language practices and academic outcomes of preschool children. Science 333:964-967. doi: 10.1126/science.1204526.

Dickinson, David K., \& Porche, Michelle V. (2011). Relation between language experiences in preschool classrooms and children's kindergarten and fourth-grade language and reading ability. Child Development 82(3):870-886.

Dyson, Anne H. (2002). The drinking god factor: A writing development remix for "all” children. Written Communication 19(4):545-577. doi: 10.1177/074108802238009.

Eggins, Suzanne, \& Slade, Diana (2005). Analysing casual conversation. London: Equinox Publishing. 
Engel, S. (1997). The guy who went up the steep nicken: The emergence of storytelling during the first three years. Zero to Three 17(3):1, 3-9.

Goodwin, Marjorie H. (1993). Participation frameworks within girls' and boys' disputes. Gender and Conversational Interaction:110.

Gynne, Annaliina \& Bagga-Gupta, Sangeeta (2013). Young people’s languaging and social positioning: Chaining in "bilingual" educational settings in Sweden. Linguistics and Education 24:479-496.

Halliday, Michael A.K. (1975). Learning how to mean: Explorations in the development of language and meaning. Baltimore: University Park Press.

Halliday, Michael A.K., \& Matthiessen, C.M.I.M. (2004). Introducing functional grammar. New York: Edward Arnold.

Hasan, Ruqaiya (1984). The nursery tale as genre. Nottingham Linguistics Circular 12:71-102.

Heath, Shirley Brice. (1983). Ways with words: Language, life, and work in communities and classrooms. Cambridge: Cambridge University Press.

Hoff-Ginsberg, Erika (1991). Mother-child conversation in different social classes and communicative settings. Child Development 62(4):782-796.

Huttenlocher, Janellen, Vasilyeva, Marina, Cymerman, Elina, \& Levine, Susan (2002). Language input and child syntax. Cognitive Psychology 45(3):337-374. doi: http://dx.doi.org/ 10.1016/S0010-0285(02)00500-5.

Hyon, Sunny \& Sulzby, Elizabeth (1994). African American kindergarteners' spoken narratives: Topic associating and topic centered styles. Linguistics and Education 6(2):121-152. Jimenez-Silva, Margarita \& McCabe, Allyssa (1996). Vignettes of the continuous and family 
ties: Some Latino American traditions. In A. McCabe (Ed.), Chameleon readers:

Teaching children to appreciate all kinds of good stories (pp. 116-136). New York: McGraw-Hill.

Justice, Laura M., McGinty, Anita S., Zucker, Tricia, Cabell, Sonia Q., \& Piasta, Shayne B. (2013). Bi-directional dynamics underlie the complexity of talk in teacher-child playbased conversations in classrooms serving at-risk pupils. Early Childhood Research Quarterly 28:496-508. doi: http://dx.doi.org/10.1016/j.ecresq.2013.02.005.

Khimji, Fatima \& Maunder, Rachel E. (2012). Meditational tools in story construction: An investigation of cultural influences on children's narratives. Journal of Early Childhood Research 10(3):294-308.

Kyratzis, Amy (2000). Tactical uses of narratives in nursery school same-sex groups. Discourse Processes 29(3):269-299.

Küntay, Aylin C., \& Şenay, İbrahim. (2003). Narratives beget narratives: Rounds of stories in Turkish preschool conversations. Journal of Pragmatics 35(4):559-587.

Labov, William \& Waletzky, Joshua (1967). Narrative analysis: Oral versions of personal experience. In J. Helm (Ed.) Essays on the Verbal and Visual Arts: Proceedings of the 1966 Annual Spring Meeting of the American Ethnological Society. Seattle: University of Washington Press.

Martin, James R. (1984). Types of writing in infants and primary school. Paper presented at the Reading, writing, spelling: Proceedings of the Fifth MacArthur Reading/Language Symposium.

Martin, James R. (2009). Genre and language learning: A social semiotic perspective. 
Linguistics and Education 20(1):10-21.

Martin, James R., \& Rose, David (2008). Genre relations: Mapping culture. London: Equinox.

McCabe, Allyssa (1997). Cultural background and storytelling: A review and implications for schooling. The Elementary School Journal 97(5):453-473.

McCabe, Allyssa, Bailey, Alison L., \& Melzi, Gigliana (Eds.). (2008). Spanish-language narration and literacy: Culture, cognition, and emotion. Cambridge, England: Cambridge University Press.

McCabe, Allyssa \& Peterson, Carol (1991). Getting the story: Parental styles of narrative elicitation and developing narrative skills. In A. McCabe \& C. Peterson (Eds.), Developing narrative structure (pp. 217-253). Hillsdale, NJ: Erlbaum.

McNamee, Gillian D. (1990). Learning to read and write in an inner-city setting: A longitudinal study of community change. In L.C. Moll (Ed.), Vygotsky and education: Instructional implications and applications of sociohistorical psychology. Cambridge:Cambridge University Press.

McNamee, Gillian D. (1992). Vivian Paley's ideas at work in Head Start. The Quarterly Newsletter of the Laboratory of Comparative Human Cognition 14(3):68-70.

Michaels, Sarah (1981). "Sharing time”: Children's narrative styles and differential access to literacy. Language in Society 10(3):423-442.

Michaels, Sarah (2005). Can the intellectual affordances of working-class storytelling be leveraged in school? Human Development 48:136-145. DOI: 10.1159/000085516

Michaels, Sarah (2006). Narrative presentations: An oral preparation for literacy with first graders. In J.C. Cook-Gumperz (Ed.), The social construction of literacy. London: 
Cambridge University Press.

Miller, Peggy J., Koven, Michele, \& Lin, Shumin (2011). Narrative. In A. Duranti, E. Ochs, \& B.B. Schieffelin (Eds.), Handbook of language socialization (pp. 190-208). Hoboken, NJ:Wiley-Blackwell.

Miller, Peggy J., Chen, Eva Chian-Hui, \& Olivarez, Megan (2014). Narrative making and remaking in the early years: Prelude to the personal narrative. In B. Schiff (Ed.), Rereading personal narrative and life course: New directions for child and adolescent development 145:15-27.

Minami, Masahiko (1996). Japanese preschool children's narrative development. First Language 16:339-363.

Minami, Masahiko (2002). Culture-specific language styles: The development of oral narrative and literacy. New York: Multilingual Matters.

Minami, Masahiko \& McCabe, Allyssa (1991). Haiku as a discourse regulation device: A stanza analysis of Japanese children's personal narratives. Language in Society 20(4):577-599.

Nelson, Katherine (Ed.) (2006). Narratives from the crib. Cambridge: Harvard University Press. Nicolopoulou, Ageliki, McDowell, Judith, \& Brockmeyer, Carolyn (2006). Narrative play and emergent literacy: Storytelling and story-acting. In D.G. Singer, R.M. Golinkoff, \& K. Hirsh-Pasek (Eds.), Play=learning: How play motivates and enhances children's cognitive and social-emotional growth (pp. 124-144). New York: Oxford University Press.

Paley, Vivien Gussin (1984). Boys and girls: Superheroes in the doll corner. Chicago:University of Chicago Press. 
Paley, Vivien Gussin (1986). Mollie is three: Growing up in school. Chicago:University of Chicago Press.

Paley, Vivien Gussin (1990). The boy who would be a helicopter: The uses of storytelling in the classroom. Cambridge, MA: Harvard University Press.

Peterson, Carol \& McCabe, Allyssa (1983). Developmental psycholinguistics: Three ways of looking at a child's narrative: New York:Plenum Press.

Peterson, Carol \& McCabe, Allyssa (1991). Linking children's connective use and narrative macrostructure. In A. McCabe \& C. Peterson (Eds.), Developing narrative structure (pp. 29-53). Hillsdale, NJ: Erlbaum.

Plum, Guenter A. (2004). Text and contextual conditioning in spoken English, volume one: Text. Sydney eScholarship Repository. Retrieved from http://hdl.handle.net/2123/608. Rogoff, Barbara (2003). The cultural nature of human development. New York: Oxford University Press.

Rothery, Joan, \& Stenglin, Maree. (1997). Entertaining and instructing: Exploring experience through story. In F. Christie \& J.R. Martin (Eds.), Genre and institutions: Social processes in the workplace and school. London:Cassell.

Schick, Adina \& Melzi, Gigliana (2010). The development of children's oral narratives across contexts. Early Education \& Development 21(3):293-317.

Schleppegrell, Mary J. (2004). The language of schooling: A functional linguistics perspective. New Jersey: Lawrence Erlbaum Associates.

Snow, Catherine E., \& Beals, Diane E. (2006). Mealtime talk that supports literacy development. New Directions for Child and Adolescent Development 111:51-66. doi: 10.1002/cad.154. 
Souto-Manning M, Dernikos B, Yu HM (2016) Rethinking normative literacy practices, behaviors, and interactions: Learning from young immigrant boys. Journal of Early Childhood Research 14(2):163-80.

Stein, Nancy L. \& Albro, Elizabeth R. (1994). The development of the story concept. Chicago, IL:University of Chicago.

Stein, Nancy L. \& Albro, Elizabeth R. (1997). Building complexity and coherence: Children's use of goal-structured knowledge in telling stories. In B. Bamberg (Ed.), Narrative development: Six approaches. Mahwah, NJ:Lawrence Erlbaum Associates.

Stein, Nancy L. \& Glenn, Christine G. (1979). An analysis of story comprehension in elementary school children. In R.O. Freedle (Ed.), Advances in discourse processes: New directions in discourse processing. Norwood, NJ:Ablex.

Teaching Strategies. (2013). The creative curriculum for preschool, fifth edition. Washington D.C.:Teaching Strategies.

Vygotsky, Lev S. (1978). Mind in society: The development of higher psychological processes. Cambridge, MA:Harvard University Press.

Weizman, Zehava O., \& Snow, Catherine E. (2001). Lexical input as related to children's vocabulary acquisition: Effects of sophisticated exposure and support for meaning. Developmental Psychology 37(2):265-279. 